\title{
Correction: Defining the microbial transcriptional response to colitis through integrated host and microbiome profiling
}

\author{
Nicholas Edward llott ${ }^{1} \cdot$ Julia Bollrath ${ }^{1,2} \cdot$ Camille Danne $^{1} \cdot$ Chris Schiering $^{3} \cdot$ Matthew Shale $^{4} \cdot$ Krista Adelmann $^{1}$. \\ Thomas Krausgruber $^{5} \cdot$ Andreas Heger $^{6} \cdot$ David Sims $^{6} \cdot$ Fiona Powrie $^{1}$
}

Published online: 20 November 2019

(c) The Author(s) 2019. This article is published with open access

\section{Correction to: The ISME Journal}

$$
\text { https://doi.org/10.1038/ismej.2016.40 }
$$

Since publication of the original paper the authors realised the following funding body was missing from the article's Acknowledgements:

"FP and this work was also supported by the European Research Council (ERC, Advanced Grant Ares(2013) 3687660)".

The authors apologise for any inconvenience caused.

These authors contributed equally: Nicholas Edward Ilott, Julia Bollrath, Camille Danne

The original article can be found online at https://doi.org/10.1038/ ismej.2016.40.

\section{Fiona Powrie}

fiona.powrie@kennedy.ox.ac.uk

1 Kennedy Institute of Rheumatology, University of Oxford, Oxford, UK

2 Institute for Tumor Biology and Experimental Therapy, Georg-Speyer-Haus, Frankfurt am Main, Germany

3 The Francis Crick Institute, Mill Hill Laboratory, London, UK

4 Translational Gastroenterology Unit, Experimental Medicine, Nuffield Department of Medicine, John Radcliffe Hospital, Oxford, UK

5 CeMM Research Center for Molecular Medicine of the Austrian Academy of Sciences, Vienna, Austria

6 Computational Genomics Analysis and Training (CGAT), MRC Functional Genomics Unit, Department of Physiology, Anatomy and Genetics, University of Oxford, Oxford, UK
Open Access This article is licensed under a Creative Commons Attribution 4.0 International License, which permits use, sharing, adaptation, distribution and reproduction in any medium or format, as long as you give appropriate credit to the original author(s) and the source, provide a link to the Creative Commons license, and indicate if changes were made. The images or other third party material in this article are included in the articleâ€ ${ }^{\mathrm{TM}_{\mathrm{S}}}$ Creative Commons license, unless indicated otherwise in a credit line to the material. If material is not included in the articleâ $€^{\mathrm{TM}_{\mathrm{S}}}$ Creative Commons license and your intended use is not permitted by statutory regulation or exceeds the permitted use, you will need to obtain permission directly from the copyright holder. To view a copy of this license, visit http://crea tivecommons.org/licenses/by/4.0/. 